\title{
Kinematic Analysis of SAVGS
}

\author{
Samnang Chheang and Unggul Wasiwitono \\ Department of Mechanical Engineering, Institut Teknologi Sepuluh Nopember, Surabaya \\ e-mail: chheangsamnang007@gmail.com
}

\begin{abstract}
Abstrak-The SAVGS as active low bandwidth retrofitted in the double-wishbone arrangement is studied. In this study, two configurations of arm linkages and variations of single-link are investigated. A linear equivalent model of the quarter car is presented based on energy conservation principles. The estimated results captured that the spring stiffness and damping coefficients of the equivalent model behave smaller when lengthening the lower arm geometry. On the other hand, the spring stiffness, damping coefficients, and linear actuator speed of the equivalent model increase when lengthening the singlelink.
\end{abstract}

Keywords-Active Low Bandwidth, Double-wishbone Arrangement, Quarter-Car, Variable Geometry.

\section{INTRODUCTION}

$\mathrm{V}$ EHICLE suspension essentially isolates the disturbance propagated from uneven road surface to the vehicle body that assures: passenger comfort (root mean square of vertical body acceleration), vehicle road holding (tire deflection), and overall vehicle stability. There are three types of suspension design: passive suspension, semi-active suspension, and active suspension [1]. The vibration, which reduced the vehicle frame life and affected biological passengers [2], is aimed to be eliminated as much as possible. Regarding these, especially for passenger comfort, the active suspensions are widely assessed that they provided the best capabilities among the aforementioned types [3].

The active suspensions encouraged to equip in the luxury vehicle are continuously studied on their performance improvement, the essential approach is started from the quarter-car model [1], [3]-[11], typically utilizing linear and non-linear models. However, in the real application, the suspension lower end-strut is seldom connected to the center mass of unsprung mass, which leads the suspension system to be non-linear. There are different strategies of performance studied on suspension linkage and controller types. Several works study the influences of linkage geometry of the suspension. In [12], it has been reported that the variation of the double-wishbone lower arm significantly influenced the suspension performance. In addition, a few controllers have been proposed with the promising result; LQR [4]-[6], [9], [13]-[15]; LQG [7], [8]; and robust control H-infinity [1], [3], [10]-[12]

Nonetheless, active suspension in vehicle production still fails, especially for the high bandwidth, due to the several drawbacks, such as energy demand, lower compactness, and complexity [11]. Moreover, the passive suspension has limited capability due to the limited suspension stroke [8], less adjustability of force, and damping coefficient. To ease

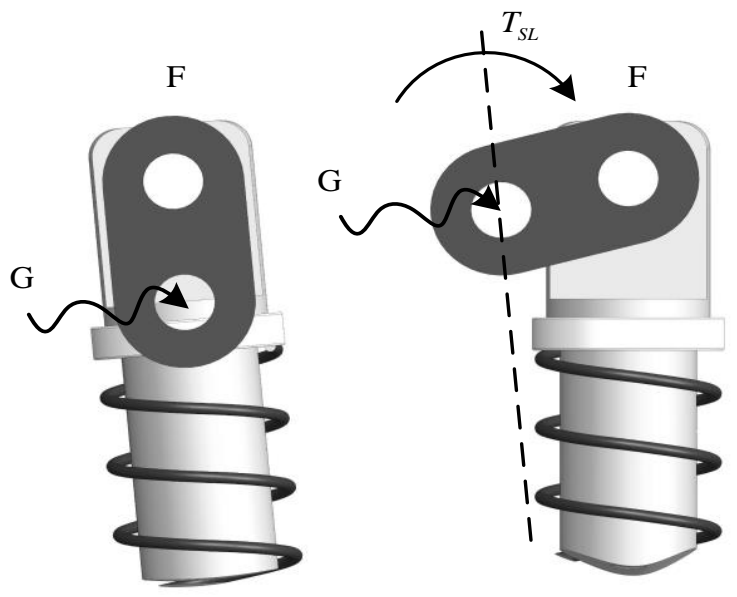

Figure 1. SAVGS concept in the passive suspension.

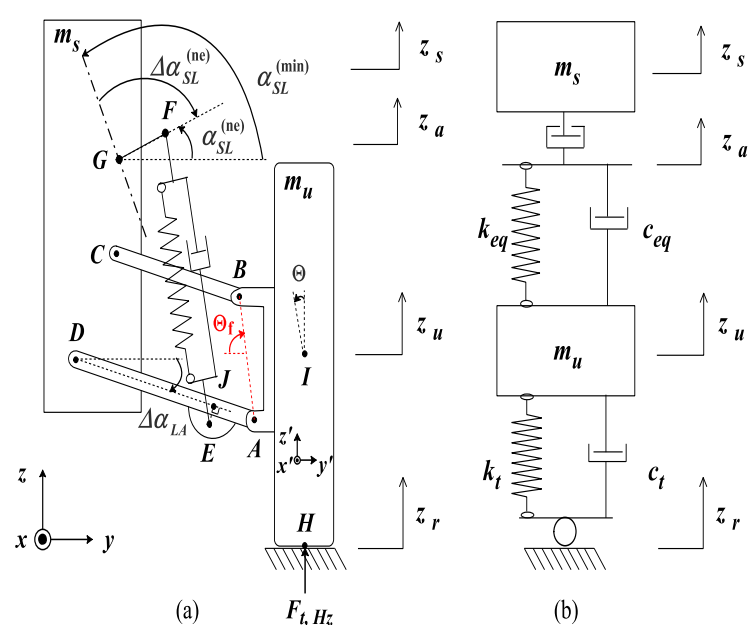

Figure 2. Quarter model; (a) double-wishbone arrangement, (b) linear. model.

these conflicted solutions, the extensive studies and implementing of active low bandwidth suspension have proposed in the literature [1], [8], [9]; it has been reported that the suspension performance is compatible with the high bandwidth active suspension in term of ride comfort without violating the given constraints.

Recently, on the other hand, an alternative suspension concept classified as low bandwidth of which, Series Active Variable Geometry Suspension (SAVGS) has been introduced. The SAVGS maintains the features of passive systems and minimize the disadvantage effects of other active solutions [16]. The passive or semi-active suspensions in which single-link (SL) located between chassis and 
The $6^{\text {th }}$ International Seminar on Science and Technology (ISST) 2020

July $25^{\text {th }}, 2020$, Institut Teknologi Sepuluh Nopember, Surabaya, Indonesia

Table 1.

Suspension System Parameters

\begin{tabular}{|c|c|c|c|}
\hline & & "Value & \\
\hline Parameter (unit) & Configuration 1 & & Configuration 2 \\
\hline Sprung mass, $\boldsymbol{m}_{\boldsymbol{s}}(\mathrm{kg})$ & & 0.5 & \\
\hline Unsprung mass, $\boldsymbol{m}_{u}(\mathrm{~kg})$ & & 0.2 & \\
\hline Suspension stiffness coefficient, $\boldsymbol{k}_{\text {Sus }}(\mathrm{N} / \mathrm{m})$ & & 652.45 & \\
\hline Suspension damping coefficient, $\boldsymbol{c}_{\text {Sus }}(\mathrm{N} . \mathrm{s} / \mathrm{m})$ & & 38.3 & \\
\hline Suspension unloaded length, $\boldsymbol{l}_{\text {Sus } 0}(\mathrm{~mm})$ & & 92.75 & \\
\hline Upper arm length, $\overline{\boldsymbol{B C}}(\mathrm{mm})$ & 81.54 & & 91.43 \\
\hline Lower arm length, $\overline{\boldsymbol{A D}}(\mathrm{mm})$ & 101.34 & & 111.26 \\
\hline
\end{tabular}
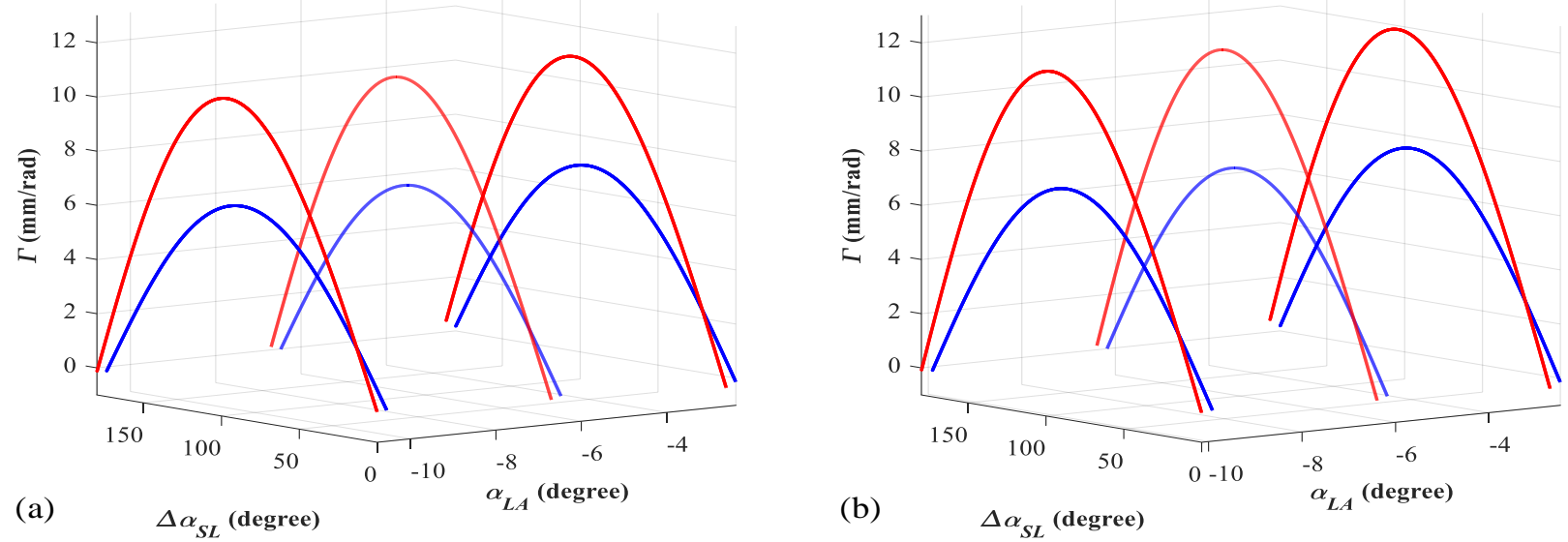

Figure 3. $\Gamma$ function, (a) configuration 1 and (b) configuration 2 (blue single-link case 1, red single-link case 2).

suspension end-strut [17] are shown in Figure 1. This link is controlled on rotation respected to chassis point (point $\mathrm{G}$ ) by an epicyclic gearbox of an electric actuator to adjust the force of suspension strut [10] so that there is no added unsprung mass and little increase sprung mass.

The major study approaches of these researches, which have been studied with double-wishbone arrangement [1], [3], [10], [11], [16]-[19]; focus on linear and non-linear models. In spite of the availability of software-aided for nonlinear models and virtual tests, they are not the most appropriate method for controller synthesis [11]. Linear models, on the other hand, simplify the study of the system dynamics for simulation as well as experimental perspective [1], [10], [11]. Additionally, the quarter-car test rig of an actual grand tourer rear axle has been studied in [1], with the promising result fail-safe operation, and lower power consumption, of which the SAVGS actuator power is below 500W. Despite the advantages of SAVGS features, it is still facts with how to make a linear equivalent model appropriately and studied at stand-alone geometry.

This paper aims to study the kinematic analysis and linear equivalent model of the double-wishbone quarter-car that retrofitted with SAVGS. More precisely, the influence of two cases of single-link length and differences in linkage geometries of kinematic suspension are further studied.

\section{EMBODIMENT OF SAVGS IN A QUARTER-CAR}

As shown in Figure 1, the left suspension is at the static equilibrium as well as purely in passive mode when point $F$ is above point $G$, and the single-link (SL) is aligned with the suspension. Conversely, it becomes active low bandwidth suspension when the SL rotates respect to point $G$. The action of SL, which is led by applying the torque $\left(T_{S L}\right.$ or angle $\left(\alpha_{S L}\right)$ or angle speed $\left(\dot{\alpha}_{S L}\right)$ [11], has adjusted the force and the installation ratio of suspension as well [17].

Error! Reference source not found. illustrates the SAVGS retrofitted in the double-wishbone quarter-car model (a) and its linear equivalent model (b). The former model comprises the wheel assembly (unsprung mass, $m_{u}$ ) firmly linked to the chassis (sprung mass, $m_{s}$ ) by the lower arm $(\overline{A D})$ and upper arm $(\overline{B C})$ using the revolute joint. The suspension end strut (point $F$ ) is adjusted due to the rotation of SL $(\overline{F G})$ for any clockwise angles $\left(\Delta \alpha_{S L}\right)$ as the positive direction from the static equilibrium state, which is the minimal state of SL $\left(\alpha_{S L}^{(\min )}\right)$. This model (a) is made as equivalent to the latter model (b) base on theoretical analysis discussed in the next subsection.

\section{A. Kinematic Analysis and Linear Equivalent Model of SAVGS}

The equivalent model of SAVGS, which is preferable for the controller synthesis, is discussed in this section based on the kinematic linkage analysis as well as the following assumptions. First assumption, both models have the same $m_{s}$ and the same $m_{u}$. Second assumption, $\overline{F G}$ projected speed in the $z$-direction is enabled to make a relationship with the linear actuator speed, $\dot{u}=\dot{z}_{s}-\dot{z}_{a}$. Third assumption, geometric equivalence, the vertical suspension deflections of models (a) and (b), $z_{a}-z_{u}$, are the same and the tire deflections of those of models, $z_{u}-z_{r}$ are the same as well 
The $6^{\text {th }}$ International Seminar on Science and Technology (ISST) 2020

July $25^{\text {th }}, 2020$, Institut Teknologi Sepuluh Nopember, Surabaya, Indonesia
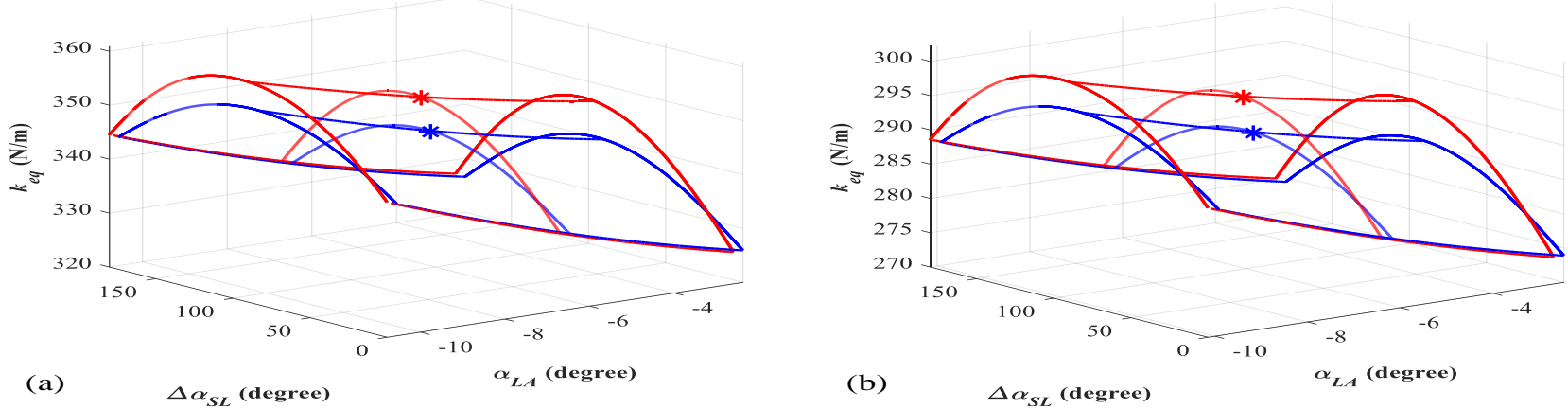

Figure 4. Variation of equivalent spring stiffness, (a) configuration 1 and (b) configuration 2 (blue single-link case 1, red single-link case 2).
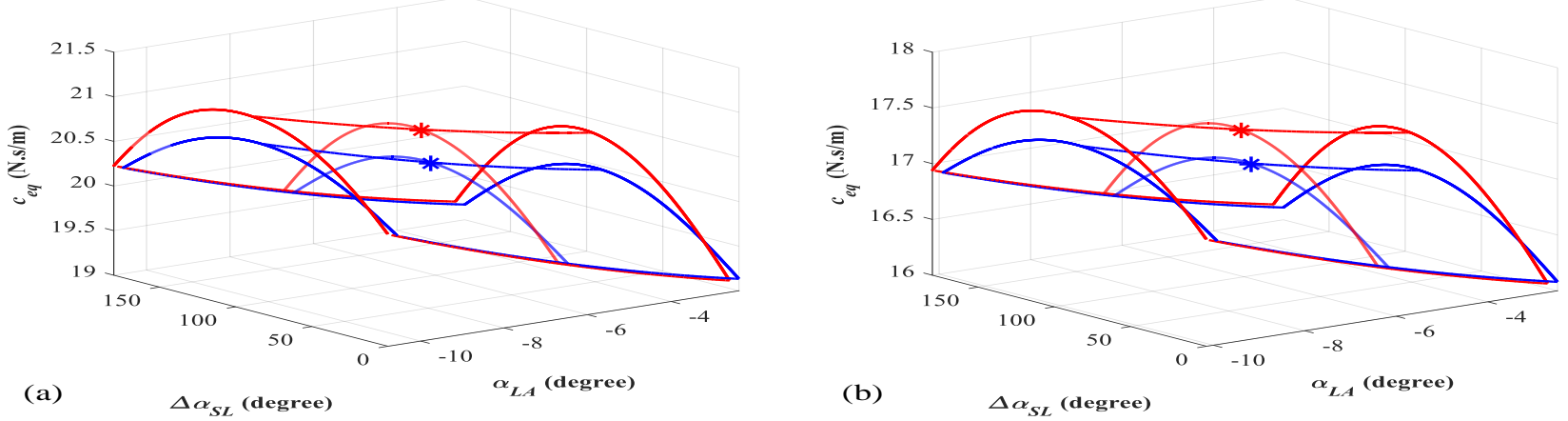

Figure 5. Variation of equivalent damping coefficient, (a) configuration 1 and (b) configuration 2 (blue single-link case 1, red single-link case 2).

[1]. Fourth assumption, actuator equivalence, the power consumption of rotary actuator in model (a) is the same as that of linear actuator in model (b) [1] so that the formula can be derived as:

$$
T_{S L} \dot{\alpha}_{S L}=F_{S u s}^{*} \dot{u}
$$

where $\dot{\alpha}_{S L}$ is the angular speed of single-link, $F_{S u s}^{*}$ is suspension force of model (b). $T_{S L}$ can be derived by the principle of virtual power acting on the SL. The formula illustrated that:

$$
T_{S L}=F_{\text {Sus }} \frac{d l_{\text {Sus }}}{d \alpha_{S L}}
$$

where $F_{\text {Sus }}$ and $l_{\text {Sus }}$ is suspension force and suspension length in model (a), respectively. Starting from the static equilibrium state, the suspension deflected length of model (a) is prioritized to be defined to figure out the $\alpha_{S L}^{(\min )}$ in the sequence step. Applying the principle of virtual work in [1] acted in model (a) by suspension force:

$$
F_{\text {Sus }}^{\text {se }} \delta l_{\text {Sus }}+m_{u} g \delta I_{z}=F_{t, H_{z}}^{s e} \delta H_{z}
$$

where $F_{\text {Sus }}^{s e}, F_{t, H_{Z}}^{s e}, g$, and $H_{z}$ are; the suspension force of model (a) at static equilibrium denoted as (se), the tire force at static equilibrium, the gravitational acceleration, and the displacement of point $H$ in the z-direction, respectively. $F_{t, H_{Z}}^{s e}$ and $F_{\text {Sus }}^{\text {se }}$ can be defined as:

$$
F_{t, H_{z}}^{s e}=\left(m_{s}+m_{u}\right) g
$$

$$
F_{\text {Sus }}^{\text {se }}=k_{\text {Sus }}\left(l_{\text {Sus } 0}-l_{\text {Sus }}^{\text {se }}\right)
$$

where $l_{\text {Sus } 0}$ is unloaded suspension length and $l_{\text {Sus }}^{\text {se }}$ is static suspension length of model (a). Defining $R_{\text {Sus }}$ as the installation ratio of suspension in model (a):

$$
R_{\text {Sus }}=\frac{d l_{S u s}}{d I_{Z}}=\frac{d l_{S u s}}{d \alpha_{L A}} \frac{d \alpha_{L A}}{d I_{Z}}
$$

where $I_{Z}$ is the displacement of point $I$ in the $z$-axis, $\alpha_{L A}$ is the clockwise angle of lower arm respected to the horizontal axis, substituting (5) and (4) into (3) as well as assuming $\delta H_{z} \approx \delta I_{z}$ due to the small chamber angles, $l_{\text {Sus }}^{\text {se }}$ can be determined as:

$$
l_{\text {Sus }}^{\text {se }}=l_{\text {Sus } 0}-\frac{m_{s} g}{k_{\text {Sus }} R_{\text {Sus }}^{\text {se }}}
$$

The instant suspension length can be defined through kinematic analysis:where

$l_{\text {Sus }}=\overline{E F}=$
$\sqrt{\left(\overline{D G}_{y}+c_{2} l_{S L}-c_{1} \overline{D J}+s_{1} \overline{E J}\right)^{2}+\left(\overline{D G}_{z}+s_{2} l_{S L}+s_{1} \overline{D J}+c_{1} \overline{E J}\right)^{2}}(7$

Where:

$c_{1}=\cos \left(\Delta \alpha_{L A}\right)$

$c_{2}=\cos \left(\alpha_{S L}^{(\min )}-\Delta \alpha_{S L}\right)$

$s_{1}=\sin \left(\Delta \alpha_{L A}\right)$

$s_{2}=\sin \left(\alpha_{S L}^{(\min )}-\Delta \alpha_{S L}\right)$

and the subscript $y$ and $z$ indicate the projections in the $y$ and $z$ axes, respectively. Therefore, the term $\frac{d l_{S u s}}{d \alpha_{S L}}$ in (2) can be 
The $6^{\text {th }}$ International Seminar on Science and Technology (ISST) 2020

July $25^{\text {th }}$, 2020, Institut Teknologi Sepuluh Nopember, Surabaya, Indonesia
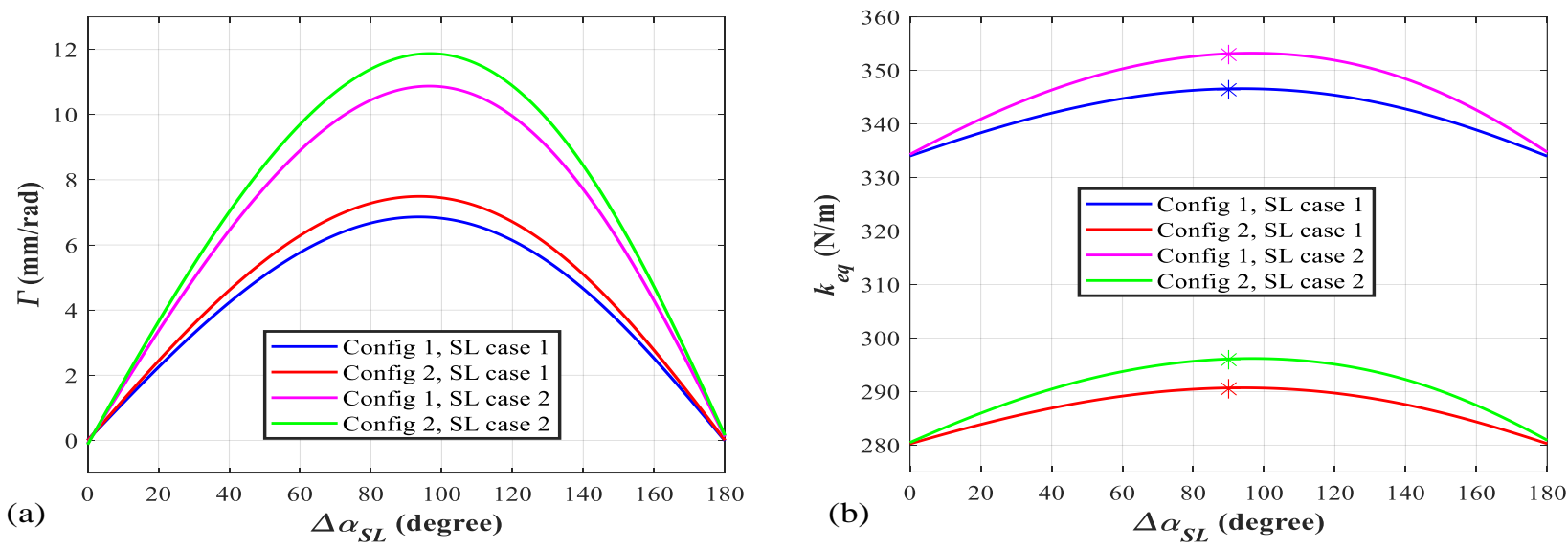

Figure 6. Variation of $\Gamma$ (a) and equivalent spring stiffness (b) defined at the nominal state of the lower arm.

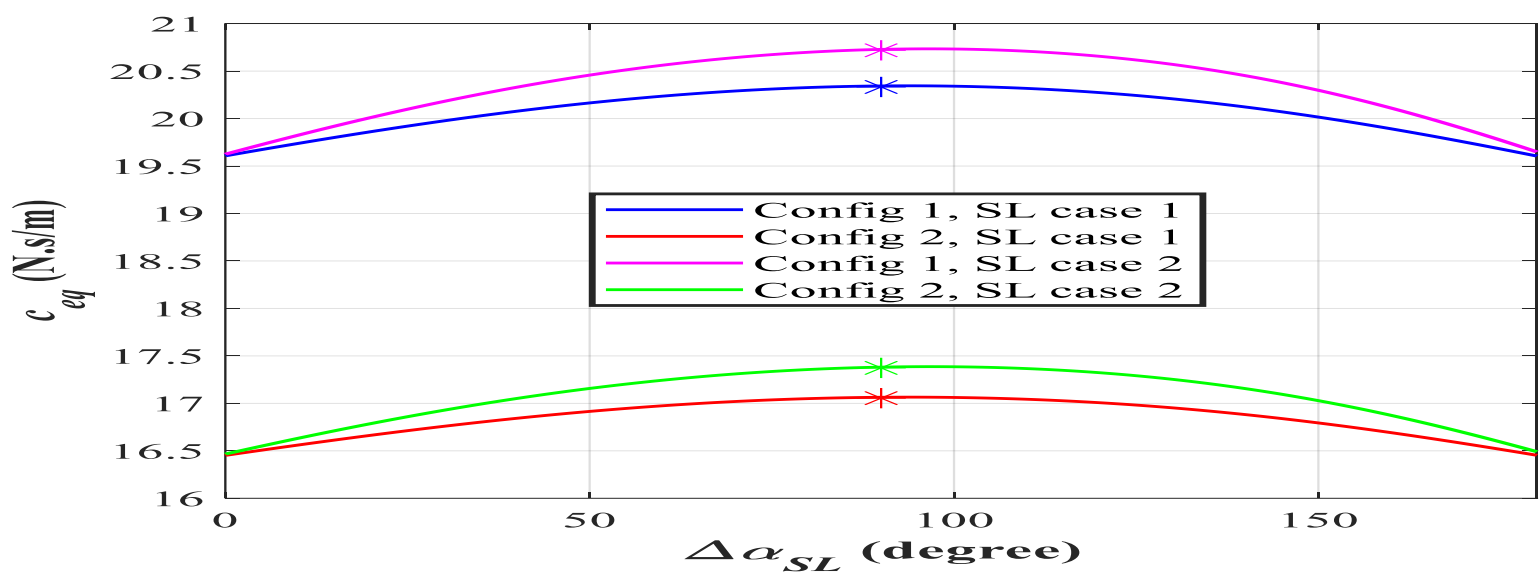

Figure 7. Variation of equivalent damping coefficient defined at the nominal state of the lower arm.

calculated via the derivative of $l_{S u s}$ respects to $\alpha_{S L}$, derived as

$$
\begin{gathered}
\frac{d l_{S u s}}{d \alpha_{S L}}=\frac{l_{S L}}{l_{\text {Sus }}}\left[c_{2} \overline{D G}_{z}-s_{2} \overline{D G}_{y}+\overline{D J}\left(c_{1} s_{2}+c_{2} s_{1}\right)\right. \\
\left.+\overline{E J}\left(c_{1} c_{2}-s_{1} s_{2}\right)\right]
\end{gathered}
$$

where $l_{S L}$ is the single-link length. Furthermore, the term $\frac{d l_{S u s}}{d \alpha_{L A}}$ in (5) can be derived via the derivative of $l_{S u s}$ respects to $\alpha_{L A}$ :

$$
\begin{gathered}
\frac{d l_{S u s}}{d \alpha_{L A}}=\frac{1}{l_{\text {Sus }}}\left[a_{1} s_{1}+a_{2} c_{1}+l_{S L} \overline{D J}\left(s_{1} c_{2}+s_{2} c_{1}\right)\right. \\
\left.+l_{S L} \overline{E J}\left(c_{1} c_{2}-s_{1} s_{2}\right)\right]
\end{gathered}
$$

where

$a_{1}=\overline{D J} \cdot \overline{D G}_{y}-\overline{E J} \cdot \overline{D G}_{z}$,

$a_{2}=\overline{E J} \cdot \overline{D G}_{y}+\overline{D J} \cdot \overline{D G}_{z}$,

Term $\frac{d \alpha_{L A}}{d I_{z}}$ in (5) is more complicated in deriving its equation. However, this term can be written:

$$
\frac{d \alpha_{L A}}{d I_{Z}}=\frac{1}{\frac{d I_{Z}}{d \alpha_{L A}}}
$$

where $\frac{d I_{z}}{d \alpha_{L A}}$ solely depends on the passive geometry, can be computed as

$$
\frac{d I_{z}}{d \alpha_{L A}}=\frac{d \Theta}{d \alpha_{L A}}\left(\overline{A I}_{y^{\prime}} \cos \Theta-\overline{A I}_{z^{\prime}} \sin \Theta\right)-c_{1} \overline{A D}
$$

where $\Theta$ is the angle of wheel respected to the vertical axis that can be calculated via kinematic analysis of linkage

$$
\begin{aligned}
\Theta=\Theta_{f}-\arccos & \left(\frac{\overline{A C}_{y}}{\overline{A C}}\right) \\
& -\arccos \left(\frac{\overline{A B}^{2}+\overline{A C}^{2}-\overline{B C}^{2}}{2 \overline{A B} \cdot \overline{A C}}\right)
\end{aligned}
$$

where $\Theta_{f}$ is the angle between $\overline{A B}$ and $-y^{\prime}$ axis,

$\overline{A C}=\sqrt{\left(c_{1} \overline{A D}-\overline{C D}_{y}\right)^{2}+\left(s_{1} \overline{A D}+\overline{C D}_{z}\right)^{2}}$

$\overline{A C}_{y}=c_{1} \overline{A D}-\overline{C D}_{y}$

$\overline{A C}_{z}=s_{1} \overline{A D}+\overline{C D}_{z}$

and the term $\frac{d \Theta}{d \alpha_{L A}}$ can be obtained by derivation of $\Theta$ respects to $\alpha_{L A}$ where required $\frac{d \overline{A C}}{d \alpha_{L A}}$ : 
The $6^{\text {th }}$ International Seminar on Science and Technology (ISST) 2020

July $25^{\text {th }}, 2020$, Institut Teknologi Sepuluh Nopember, Surabaya, Indonesia

$$
\frac{d \overline{A C}}{d \alpha_{L A}}=\frac{\overline{A D}}{\overline{A C}}\left(s_{1} \overline{C D}_{y}+c_{1} \overline{C D}_{z}\right)
$$

The suspension force $F_{\text {Sus }}$ in model (a) and that of $F_{\text {Sus }}^{*}$ in model (b) are related such that:

$$
F_{\text {Sus }}^{*}=R_{\text {Sus }} F_{\text {Sus }}
$$

Applying the assumption 2, the displacement of point $F$ in $z$-direction in model (a) can be reversibly transformed that of $z_{a}$ in model (b) through $\Gamma$ function, which is shown that:

$$
\Gamma=\frac{\dot{u}}{\dot{\alpha}_{S L}}
$$

Substituting (2) and (15) to (1), $\Gamma$ can be rewritten as:

$$
\Gamma=\frac{1}{R_{\text {Sus }}} \frac{d l_{\text {Sus }}}{d \alpha_{S L}}
$$

Lastly, $k_{e q}$ and $c_{e q}$ is linear equivalent spring stiffness and damping coefficients of model (a). Both of those values can be computed through assumptions in [11] such that the rate of change of energy stored, as well as that of energy dissipation in model (a) must be the same as those of in model (b).

$$
\begin{gathered}
k_{e q}=k_{\text {Sus }} R_{\text {Sus }}^{2}-F_{\text {Sus }} \frac{d R_{\text {Sus }}}{d I_{z}} \\
c_{e q}=c_{\text {Sus }} R_{\text {Sus }}^{2}
\end{gathered}
$$

\section{RESULT AND DISCUSSION}

The parameter values for the systems in this study are listed in Table 1. Two cases of SL length are studied in each configuration, and its length is $5 \mathrm{~mm}$ and $8 \mathrm{~mm}$ for cases 1 and 2, respectively. Starting from the quarter-car linkage geometry configuration 1, in Figure 3a, the lower arm angles ranged from static equilibrium to maximum suspension deflection are $-2.3762^{\circ}$ to $-10.5589^{\circ}$ and $-2.6004^{\circ}$ to $-10.7842^{\circ}$, for case 1 and case 2 , respectively. It illustrated that $\Gamma$ significantly depended on $\Delta \alpha_{S L} ;$ at $\Delta \alpha_{S L}=0^{\circ}$ and $\Delta \alpha_{S L}=180^{\circ}$, it crosses the zero values. However, it is less effected by $\Delta \alpha_{L A}$. Variation of $\Gamma$ is reasonably small when comparing at the nominal lower arm angle state (asterisk point, lower arm angle at $-6.48^{\circ}$ and $-6.7^{\circ}$ for case 1 and case 2 , respectively) to its static state, with offset bandwidth $\sim 5.3 \%$ and $\sim 3.6 \%$ for cases 1 and 2 , respectively. In other words, for case 2 of SL, the upper bound magnitude of negative parabolic at $\Delta \alpha_{S L}=90^{\circ}$ somehow is larger than that of case 1 as shown in Figure 6 a.

Figure $4 \mathrm{a}$ and Figure $5 \mathrm{a}$ are estimated values of $k_{e q}$ and $c_{e q}$ of configuration 1, respectively. The lower arm angles of each respective case are ranged the same as in Figure 3a. At fixed SL angle, $k_{e q}$ and $c_{e q}$ are slightly, as well as low slope changed when comparing among both cases, along with the variation of lower arm angle. In contrast, both values are significantly suffered from the variation of SL angle. However at the minimum SL angle $\left(\Delta \alpha_{S L}=0^{\circ}\right)$ and the maximum SL angle $\left(\Delta \alpha_{S L}=180^{\circ}\right), k_{e q}$ and $c_{e q}$ tent to equal to their values at those states. $k_{e q}$ and $c_{e q}$ at the nominal state are a pair of case 1 and case $2 ; 346.56 \mathrm{~N} / \mathrm{m}$ and $20.34 \mathrm{~N} . \mathrm{s} / \mathrm{m}$, and $353.12 \mathrm{~N} / \mathrm{m}$ and $20.73 \mathrm{~N} . \mathrm{s} / \mathrm{m}$; respectively. Observing on these, $k_{e q}$ and $c_{e q}$ are larger than those of values in SL case 1 as shown in Figure $6 b$ and Figure 7.

Let observing on the configuration 2 of linkage geometry. The lower arm angles ranged from $-2.4769^{\circ}$ to $-9.9135^{\circ}$ and from $-2.6944^{\circ}$ to $-10.1476^{\circ}$, for case 1 and case 2 , respectively. The result features in this configuration are similar to those of configuration 1 when comparing among two cases of SL. $k_{e q}$ and $c_{e q}$, in Figure $4 \mathrm{~b}$ and Figure $5 \mathrm{~b}$, at each nominal state (asterisk point, lower arm angle at $-6.18^{\circ}$ and $-6.4^{\circ}$ for case 1 and case 2 , respectively) are: $290.69 \mathrm{~N} / \mathrm{m}$ and $17.06 \mathrm{~N} . \mathrm{s} / \mathrm{m}$, and $296.10 \mathrm{~N} / \mathrm{m}$ and $17.38 \mathrm{~N} . \mathrm{s} / \mathrm{m}$ for case 1 and case 2; respectively.

On the other hand, when comparing between configuration 1 and configuration 2 in the individual SL case, $k_{e q}$ and $c_{e q}$ presented that they are greater than those of values in configuration 1, as shown in Figure $6 \mathrm{~b}$ and Figure 7.

\section{CONCLUSION}

The kinematic and linear equivalent of SAVGS retrofitted in the double-wishbone quarter-car have been studied. Two configurations of linkage geometries, as well as two cases of single-link length, have been analyzed base on the energy conservation approach. The estimated values of $\Gamma, k_{e q}$ and $c_{e q}$ illustrated that the smaller of equivalent spring stiffness and damping coefficients occur when using the longer lower arm. Furthermore, the longer of single-link is, the larger of equivalent spring stiffness, damping coefficients, and linear equivalent actuator speed behaves as well. More interestingly, the largest of equivalent spring stiffness and damping coefficients exists when shortening the lower arm and lengthening single-link.

\section{REFERENCES}

[1] M. Yu, C. Arana, S. A. Evangelou, and D. Dini, "Quarter-car experimental study for series active variable geometry suspension," IEEE Trans. Control Syst. Technol., vol. 27, no. 2, pp. 743-759, 2017.

[2] S. Ikenaga, F. L. Lewis, J. Campos, and L. Davis, "Active suspension control of ground vehicle based on a full-vehicle model," in Proceedings of the 2000 American Control Conference. ACC (IEEE Cat. No. 00CH36334), 2000, vol. 6, pp. 4019-4024

[3] C. Cheng, S. A. Evangelou, C. Arana, and D. Dini, "Active variable geometry suspension robust control for improved vehicle ride comfort and road holding," in 2015 American Control Conference (ACC), 2015, pp. 3440-3446.

[4] Y. M. Sam, M. R. H. A. Ghani, and N. Ahmad, "LQR controller for active car suspension," in 2000 TENCON Proceedings. Intelligent Systems and Technologies for the New Millennium (Cat. No. OOCH37119), 2000, vol. 1, pp. 441-444.

[5] M. A. Nekoui and P. Hadavi, "Optimal control of an active suspension system," in Proceedings of 14th International Power Electronics and Motion Control Conference EPE-PEMC 2010, 2010, pp. T5-60.

[6] A. Agharkakli, G. S. Sabet, and A. Barouz, "Simulation and analysis of passive and active suspension system using quarter car model for different road profile," Int. J. Eng. Trends Technol., vol. 3, no. 5, pp. 636-644, 2012.

[7] C. Yue, T. Butsuen, and J. K. Hedrick, "Alternative control laws for automotive active suspensions," 1989. 
The $6^{\text {th }}$ International Seminar on Science and Technology (ISST) 2020

July $25^{\text {th }}, 2020$, Institut Teknologi Sepuluh Nopember, Surabaya, Indonesia

[8] S. R. Kristiadi and U. Wasiwitono, "Effect of feedback measurement on LQG control for Low Bandwidth Active Suspension system," in 2015 International Conference on Advanced Mechatronics, Intelligent Manufacture, and Industrial Automation (ICAMIMIA), 2015, pp. 4245.

[9] G. Koch, O. Fritsch, and B. Lohmann, "Potential of low bandwidth active suspension control with continuously variable damper," Control Eng. Pract., vol. 18, no. 11, pp. 1251-1262, 2010.

[10] M. Yu, S. A. Evangelou, and D. Dini, "Model identification and control for a quarter car test rig of series active variable geometry suspension," IFAC-PapersOnLine, vol. 50, no. 1, pp. 3376-3381, 2017.

[11] C. Arana, S. A. Evangelou, and D. Dini, "Series active variable geometry suspension application to comfort enhancement," Control Eng. Pract., vol. 59, pp. 111-126, 2017.

[12] U. Wasiwitono, A. S. Pramono, and I. N. Sutantra, "Study on influences of linkage geometry on actively controlled double wishbone suspension," in AIP Conference Proceedings, 2018, vol. 1983, no. 1, p. 30009.

[13] M. S. Kumar and S. Vijayarangan, "Design of LQR controller for active suspension system," 2006.
[14] M. Kaleemullah, W. F. Faris, and F. Hasbullah, "Design of robust Hœ, fuzzy and LQR controller for active suspension of a quarter car model," in 2011 4th International Conference on Mechatronics (ICOM), 2011, pp. 1-6.

[15] R. Darus and Y. M. Sam, "Modeling and control active suspension system for a full car model," in 2009 5th International Colloquium on Signal Processing \& Its Applications, 2009, pp. 13-18.

[16] C. Arana, S. A. Evangelou, and D. Dini, "Pitch angle reduction for cars under acceleration and braking by active variable geometry suspension," in 2012 IEEE 51st IEEE Conference on Decision and Control (CDC), 2012, pp. 4390-4395.

[17] C. Arana, S. A. Evangelou, and D. Dini, "Series active variable geometry suspension application to chassis attitude control," IEEE/ASME Trans. Mechatronics, vol. 21, no. 1, pp. 518-530, 2015.

[18] C. Arana, S. A. Evangelou, and D. Dini, "Series active variable geometry suspension for road vehicles," IEEE/ASME Trans. Mechatronics, vol. 20, no. 1, pp. 361-372, 2014.

[19] C. Arana, S. A. Evangelou, and D. Dini, "Car attitude control by series mechatronic suspension," IFAC Proc. Vol., vol. 47, no. 3, pp. 10688 10693, 2014. 